\title{
Can Ki67 immunostaining predict response to radiotherapy in oral squamous cell carcinoma?
}

\author{
G Valente, R Orecchia, S Gandolfo, M Arnaudo, R Ragona, S Kerim, G Palestro
}

\begin{abstract}
Aims-To determine whether immunohistochemical evaluation of the abatement of proliferating cells after a first course of radiotherapy could predict the final response to treatment in oral squamous cell carcinoma (SCC).

Methods-Frozen sections from 31 cases of histologically confirmed oral SCC were stained with the monoclonal antibody $\mathrm{Ki} 67$ at diagnosis and after $10 \mathrm{~Gy}$ of radiotherapy. The percentage difference of Ki67 positive cells among the biopsy specimens taken at the beginning and after $10 \mathrm{~Gy}$ was correlated with the clinical response obtained at the end of the treatment and its significance determined.

Results-The percentage of $\mathrm{Ki67}$ positive cells at diagnosis had no significant correlation with the final therapeutic result of radiotherapy. By contrast, the $32 \%$ difference of proliferating cells after 10 Gy of radiotherapy significantly differentiated responders from non-responders $(p<0.05)$. Furthermore, the abatement of the growth fraction after $10 \mathrm{~Gy}$ of radiotherapy was significantly correlated with the complete response $(p<0.01)$. Conclusions-These data show that the immunohistochemical evaluation of the abatement of Ki67 positive cells after 10 Gy of radiotherapy provides an independent variable of responsiveness to radiotherapy, allowing a reliable prediction of the final therapeutic result to be made.
\end{abstract}

(F Clin Pathol 1994;47:109-112)

and Oncology

University of Turin

G Valente

S Kerim

G Palestro

Division of

Radiotherapy

R Orecchia

R Ragona

Institute of

Odontostomatology

$S$ Gandolfo

M Arnaudo

Correspondence to:

Dr G Valente, Dipartimento

di Scienze Biomediche e

Oncologia Umana,

Uncologia Umana,

Via Santena 7, 10126

Torino, Italy.
Tia

Accepted for publication 29 July 1993 in tailoring radiotherapy to biological features apart from clinical prognostic factors, and indicators permitting reliable assessment of response to radiotherapy and prediction of its outcome would permit the early choice of a different treatment schedule-for instance, a combination of drugs and irradiation, or an alternative approach. ${ }^{12}$ The proliferative activity of target cells is a particularly suitable subject for study, as radiotherapy is predominantly directed at the cell cycle. Costa $e t a l^{3}$ evaluated $\mathrm{H}^{3}$-thymidine uptake in oral carcinomas before and after radiotherapy and found significantly different growth fractions. This technique is time consuming, however, and the interpretation of the results is not always unequivocal. A possible alternative method would be the immunohistochemical evaluation of proliferating cells. The monoclonal antibody Ki67 detects a nuclear antigen expressed in all phases of the cell cycle except $\mathrm{G}_{0},{ }^{4}$ and has been widely used to determine the growth fraction of neoplastic tissues. ${ }^{56}$ It is more reliable than $\mathrm{H}^{3}$-thymidine uptake in determining the growth fraction, ${ }^{7}$ and is a useful indicator of the proliferating population in irradiated tissues in vitro ${ }^{8}$ and in vivo. ${ }^{9}$

This study prospectively evaluated the proliferative activity of 31 cases of oral squamous cell carcinomas (SCC) at diagnosis and after the first course of radiotherapy. Because surface and nuclear antigens can be destroyed by ionising radiation, we evaluated the effect of radiotherapy after $10 \mathrm{~Gy}$. This dose achieves initial abatement of the neoplastic mass without impairing cell morphology and antigenic characteristics.

\section{Methods}

Thirty one patients with histologically confirmed oral SCC were studied (table 1). Histological grading was evaluated according to WHO criteria. ${ }^{10}$ Clinical staging at diagnosis was assessed on the basis of the TNM classification. ${ }^{11}$

All patients were given exclusive external radiotherapy. Treatment was delivered in megavolt units $\left({ }^{60} \mathrm{Cobalt}\right.$ photons or 6 millivolts $\times$ rays) on two opposite fields. Total tumour dose (conventional fractionation: 2 Gy/fraction/day, five days a week) was between 68 and 70 Gy. Positive neck nodes received an additional 6-13 million election volts, up to a total dose of $75 \mathrm{~Gy}$.

Tumor biopsy specimens were taken at the beginning of radiotherapy and after $10 \mathrm{~Gy}$, 
Table 1 Grade, stage, and Ki67 values at diagnosis

\begin{tabular}{|c|c|c|c|c|c|c|c|}
\hline \multicolumn{4}{|l|}{ Group 1} & \multicolumn{4}{|l|}{ Group 2} \\
\hline \multicolumn{4}{|c|}{ (Ki67 positive cells > 50\%) } & \multicolumn{4}{|c|}{ (Ki67 positive cells < 50\%) } \\
\hline Case No & Grade & Stage & Ki67 & Case No & Grade & Stage & Ki67 \\
\hline $\begin{array}{l}1 \\
2 \\
3 \\
4 \\
5 \\
6 \\
7 \\
8 \\
9 \\
10 \\
11 \\
12 \\
13 \\
14 \\
15\end{array}$ & $\begin{array}{l}1 \\
2 \\
1 \\
3 \\
2 \\
2 \\
3 \\
1 \\
2 \\
1 \\
2 \\
2 \\
2 \\
3 \\
2\end{array}$ & $\begin{array}{l}\text { IV } \\
\text { III } \\
\text { IV } \\
\text { III } \\
\text { III } \\
\text { III } \\
\text { III } \\
\text { II } \\
\text { III } \\
\text { III } \\
\text { IV } \\
\text { II } \\
\text { IV } \\
\text { IV } \\
\text { IV }\end{array}$ & $\begin{array}{l}53 \\
83 \cdot 6 \\
68 \cdot 3 \\
76 \cdot 6 \\
64 \cdot 8 \\
69 \cdot 2 \\
74 \\
71 \cdot 2 \\
68 \cdot 7 \\
85 \cdot 1 \\
51 \cdot 3 \\
76 \cdot 9 \\
51 \\
68 \cdot 1 \\
56\end{array}$ & $\begin{array}{l}16 \\
17 \\
18 \\
19 \\
20 \\
21 \\
22 \\
23 \\
24 \\
25 \\
26 \\
27 \\
28 \\
29 \\
30 \\
31\end{array}$ & $\begin{array}{l}2 \\
2 \\
2 \\
3 \\
1 \\
2 \\
3 \\
1 \\
2 \\
2 \\
3 \\
2 \\
2 \\
2 \\
2 \\
2\end{array}$ & $\begin{array}{l}\text { II } \\
\text { IV } \\
\text { IV } \\
\text { II } \\
\text { IV } \\
\text { IV } \\
\text { IV } \\
\text { IV } \\
\text { II } \\
\text { II } \\
\text { IV } \\
\text { IV } \\
\text { III } \\
\text { III } \\
\text { III } \\
\text { IV }\end{array}$ & $\begin{array}{l}41 \\
42 \cdot 9 \\
45 \cdot 6 \\
47 \cdot 3 \\
47 \cdot 1 \\
20 \\
21 \cdot 8 \\
14 \cdot 9 \\
28 \\
27 \cdot 3 \\
46 \cdot 6 \\
23 \cdot 5 \\
25 \\
15 \cdot 4 \\
34 \cdot 6 \\
20 \cdot 5\end{array}$ \\
\hline
\end{tabular}

immediately frozen in liquid nitrogen, and stored at $-70^{\circ} \mathrm{C}$.

Cryostat sections fixed for 10 minutes in cold acetone were incubated with $\mathrm{Ki} 67$ (Dakopatts, Copenhagen, Denmark) diluted 1 in 40. An avidin-biotin complex (ABC) immunoperoxidase method was used, as reported before. ${ }^{12}$ 3,3'-diaminobenzidine (Sigma Chemical Co, St Louis, Missouri, USA) was used as chromogen. In each case serial sections were cut and stained with haematoxylin and eosin to recognise the nonneoplastic fields and to avoid their interference in counting positive cells.

Sections before and after 10 Gy RT were examined under a $\times 40$ objective lens. Nuclei from 500 tumour cells were counted in each section, this number having been reached by the standard continuous mean technique. Different fields were chosen, both in areas with high and low numbers of positive cells, determined by assessing initially the whole of a section at a power lower than $\times 40$.

Nuclei were regarded as positive only if they showed an unequivocal brown reaction product. The Ki67 index was calculated as the percentage of positive tumour cell nuclei. The percentage difference $(\Delta)$ of $\mathrm{Ki} 67$ values between the biopsy specimens taken at the

Table 2 Abatement of Ki67 positive cells after $10 \mathrm{~Gy}$ radiotherapy (4) and correlation with clinical response

\begin{tabular}{|c|c|c|c|c|c|}
\hline \multicolumn{3}{|l|}{$>32 \% \Delta$} & \multicolumn{3}{|l|}{$<32 \% \Delta$} \\
\hline Case No & $\Delta K i 67$ & Response & Case No & $\Delta K i 67$ & Response \\
\hline $\begin{array}{r}2 \\
4 \\
5 \\
8 \\
11 \\
14 \\
16 \\
19 \\
22 \\
23 \\
28 \\
30 \\
31\end{array}$ & $\begin{array}{l}55 \\
46 \\
64 \\
73 \\
42 \\
63 \\
54 \\
53 \\
54 \\
44 \\
34 \\
38 \\
90\end{array}$ & $\begin{array}{l}\text { CR } \\
\text { PR } \\
\text { CR } \\
\text { CR } \\
\text { CR } \\
\text { NR } \\
\text { CR } \\
\text { CR } \\
\text { PR } \\
\text { PR } \\
\text { CR } \\
\text { CR } \\
\text { RP }\end{array}$ & $\begin{array}{r}1 \\
3 \\
6 \\
7 \\
9 \\
10 \\
12 \\
13 \\
15 \\
17 \\
18 \\
20 \\
21 \\
24 \\
25 \\
26 \\
27 \\
29\end{array}$ & $\begin{array}{r}29 \\
4 \\
31 \\
17 \\
28 \\
26 \\
14 \\
-18 \\
16 \\
8 \\
1 \\
28 \\
10 \\
-28 \\
20 \\
29 \\
26 \\
18\end{array}$ & $\begin{array}{l}\text { NR } \\
\text { NR } \\
\text { NR } \\
\text { PR } \\
\text { PR } \\
\text { PR } \\
\text { PR } \\
\text { PR } \\
\text { NR } \\
\text { PR } \\
C R \\
\text { PR } \\
C R \\
\text { NR } \\
C R \\
\text { PR } \\
\text { PR } \\
\text { PR }\end{array}$ \\
\hline
\end{tabular}

NR: no response; PR: partial response; CR: complete response. beginning and after 10 Gy was then evaluated.

Ten cases were counted by two independent observers (GV and SK), and on three separate occasions by the same observer (GV), to determine the inter- and intraobserver variation, respectively. The interobserver variation was $6-12 \%$; the intraobserver variation was $8 \%$.

Tumour responses were evaluated by clinical examination or a computed tomogram, or both. The grade of clinical responsiveness (complete, partial, no response) was established according to WHO criteria. Correlation between the percentage of Ki67 positive cells and response was estimated by stepwise logistic regression, and the frequency tables were evaluated using the $\chi^{2}$ test (BMPD Statistical Software, Los Angeles, California). The response after radiotherapy was correlated with the following variables: initial value of $\mathrm{Ki} 67 ; \Delta$; histological grading; and clinical staging.

\section{Results}

KI67 VALUE (tables 1 and 2)

Evaluation of Ki67 positivity was based on the presence of characteristic intranuclear granules corresponding to the chromatin distribution (fig 1). After 10 Gy radiotherapy, immunostaining showed some morphological changes, mostly in the form of large and irregular spots (fig 2).

At diagnosis the percentage of $\mathrm{Ki} 67$ positive cells ranged from $14.9 \%$ to $85 \cdot 1 \%$. We formed two groups with more (group 1, 15 cases) or less (group 2, 16 cases) than $50 \%$ Ki67 positive cells. After 10 Gy radiotherapy, the percentage decreased in 29 of 31 cases, whereas an increase of $\mathrm{Ki} 67$ positive cells was observed in two cases. A $32 \%$ (mean value) difference ( $\Delta$ ) between $\mathrm{Ki} 67$ values at the beginning and after treatment as cutoff produced 13 cases $(\Delta>32 \%)$ and 18 cases $(\Delta<32 \%)$, respectively.

\section{RADIOTHERAPY RESPONSE AND CLINICAL}

FOLLOW UP (table 2)

Clinical response was not correlated with the initial Ki67 value, stage or grade. No significant difference between the two groups was noted with regard to the final result of radiotherapy: a complete clinical response after $\mathbf{7 0}$ Gy was observed in four of 15 cases from group 1 and in seven of 16 cases from group $2 ; 11$ of 15 patients from group 1 and nine of 16 from group 2 showed no response or only a partial response $(p=0 \cdot 32)$.

By contrast, a significant different final response was noted in the function of $\Delta: \Delta$ of $>32 \%$, eight of 13 patients $(61.5 \%)$ showed a complete response compared with three of $18(16.6 \%)$ with a $\Delta$ of $<32 \%(p<0.05)$.

Logistic regression analysis showed that the abatement of the growth fraction after $10 \mathrm{~Gy}$ radiotherapy $(\Delta)$ was significantly correlated with a complete response $(p<0.01)$. Furthermore, it was more significant in grade 2 than in grades 1 and 3 patients $(p<0.05)$. 


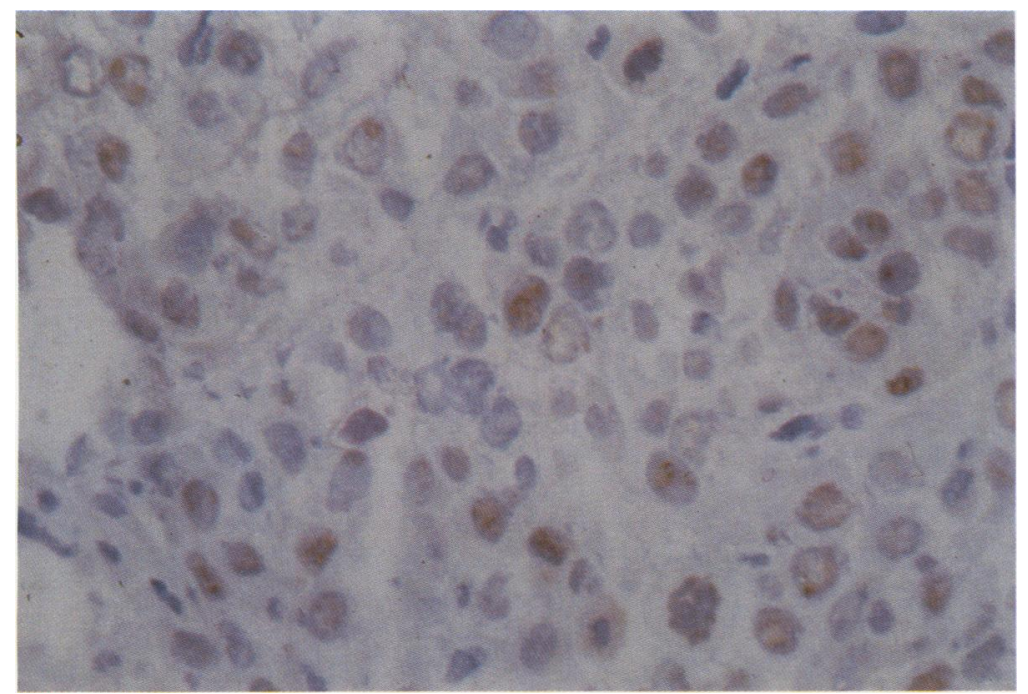

Figure 1 Squamous cell carcinoma of the oral cavity at diagnosis; numerous neoplastic cells display nuclear Ki67 positivity (ABC immunoperoxidase on cryostat section).

\section{Discussion}

The results of this prospective study show that immunohistochemical evaluation of the abatement of proliferating cells after a first course of radiotherapy is of significant assistance in predicting the final result of the treatment in oral SCC. The $32 \%$ cutoff of a reduction in Ki67 positive cells after $10 \mathrm{~Gy}$ radiotherapy distinguished responders and non-responders to the complete radiotherapy course: $61.5 \%$ patients with an abatement of proliferating cells $(\Delta)$ of more than $32 \%$ achieved a complete response at the end of treatment compared with only $16.6 \%$ with a $\Delta$ of $<32 \%$. Histological grading is regarded as an important indicator of sensitivity to radiotherapy. ${ }^{13}$ In our series, however, grade 2 patients responded better to radiotherapy than patients with grades 1 and 3 histology.

The $10 \mathrm{~Gy}$ dose seem to be critical in assessing response to radiotherapy in SCC. Similar results were obtained using a labelling

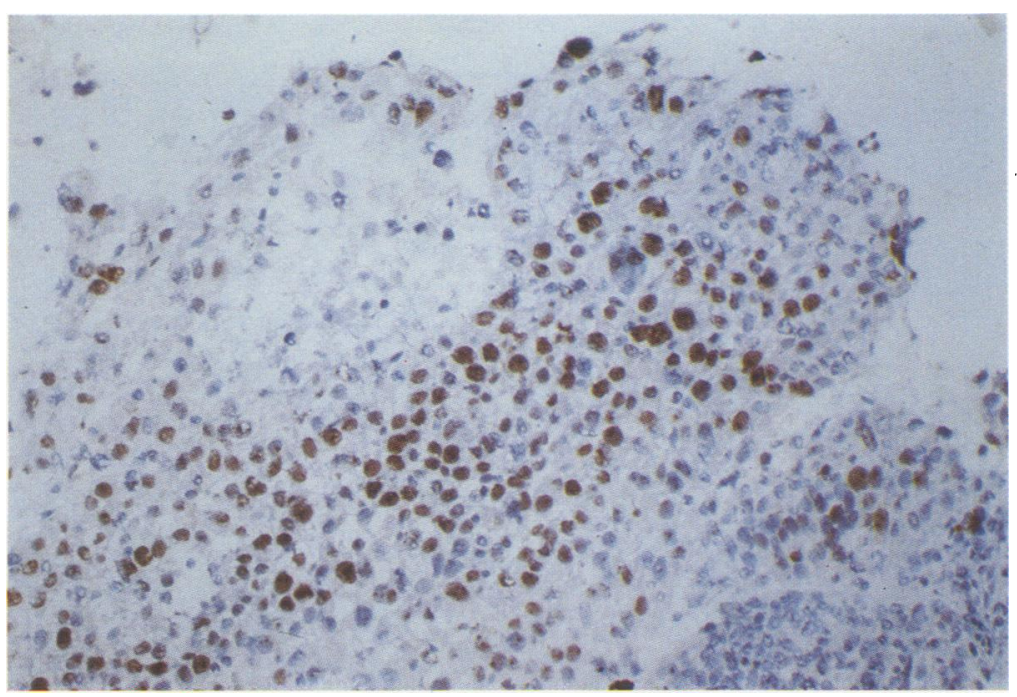

Figure 2 The same case as in fig 1; after 10 Gy of radiotherapy the abatement of Ki67 positive cells is evident; inset: Ki67 immunostaining is characterised by large and irregular spots ( $A B C$ immunoperoxidase on cryostat section). index technique. ${ }^{3}$ This dose has a strong destructive effect and influences the complete course and final result, but is not sufficient to determine the well known regressive changes of the irradiated tissues that could inhibit Ki67 positivity. Immunostaining was preserved in the tissues biopsied after $10 \mathrm{~Gy}$, and only morphological differences were observed compared with those taken before radiotherapy, as described before. ${ }^{9}$

The percentage of $\mathrm{Ki} 67$ positive cells at diagnosis is regarded as a prognostic indicator in a number of tumours. ${ }^{1415}$ In our patients, however, the final response was not related to this. Response to radiotherapy may not be restricted to the actively proliferating neoplastic tissues. For instance, it has been shown that the effect of irradiation in cultured cells is higher in some phases of the cell cycle, such as before $\mathrm{G}_{2} \mathrm{M}$; it is lower in the late $\mathrm{S}$ phase. ${ }^{16}$ Thus if the $S$ phase represents the major part of the cell cycle in a neoplastic tissue, that tissue should proliferate at a faster rate but also have a higher resistance to radiotherapy. Responsiveness to radiotherapy would therefore be difficult to evaluate using $S$ phase determination, such as labelling index and incorporation of bromodeoxyuridine. Furthermore, this could explain the occurrence of cases with higher numbers of Ki67 positive cells after treatment ( $\Delta$ negative); this phenomenon was also observed in irradiated uterine cervical tumours. ${ }^{9}$ Resistant clones with higher proliferative activity may supervene, or quiescent cells may be recruited after irradiation. In our series the occurrence of $\Delta$ negative (two patients) was an adverse variable with regard to the efficacy of radiotherapy and was associated with progression of the tumour.

Other considerations can be drawn from our data: for instance, histological grading and clinical staging were not related to the initial value of $\mathrm{Ki67}$, unlike the results of other authors. ${ }^{17-20}$ However, there have been few studies on proliferation indices in head and neck SCC. One of these ${ }^{21}$ reported that six out of nine cases histologically evaluated as poorly differentiated showed low or intermediate percentages of $\mathrm{Ki} 67$ positive cells (lower than $30 \%$ ), suggesting that proliferative activity in head and neck SCC is not always connected with the pathological features, but is an intrinsic biological character.

In conclusion, the percentage of abatement of Ki67 positive cells after the first course of radiotherapy seems to be significantly correlated with the response to radiotherapy of oral SCC, providing a predictive factor of the outcome of the treatment. Moreover, this simple and easily reproducible approach allows alternative therapeutical strategies to be introduced when the first choice treatment seems to be inadequate. Whether the percentage of abatement has any impact on survival will require further follow up studies.

This work was partially supported by MURST grants (40\%) and by AIRC (Associazione Italiana per la Ricerca sul Cancro). We thank Mrs Marilena Abbadini and Mr Nino Ferraro for their technical assistance. 
1 Peters IJ, Brock WA, Chapman JD, Wilson G, Fowler JF. Response predictors in radiotherapy: a review of
research into radiobiologically based assays. $\mathrm{Br} \mathcal{F}$ Radiol 1988;22:96-108.

2 Parkins CS, Horwich A. Prediction of tumour response to treatment. In: Steel GG, Adams GE, Horwich A eds. The biological basis of radiotherapy. 2nd Edn., Amsterdam: Elsevier 1989 .

3 Costa A, Salvatori P, Molinari R, Motta R, Cerutti A Silvestrini $\mathbf{R}$. Cell kinetics to monitor radioresponsivity in human epidermoid carcinoma. Basic Applied Histochemistry 1986;30:209-13.

4 Gerdes J, Schwab U, Lemke H, Stein H. Production of a monoclonal antibody reactive with a human nuclear antigen associated with cell proliferation. Int $\mathcal{f}$ Cancer 1983;31:13-20.

5 Crocker J. Proliferation indices in malignant lymphomas. Clin Exp Immunol 1989;67:299-308.

6 Brown DC Gatter KC Monoclonal antibody Ki-67: its use in histopathology. Histopathology 1990;17: 489-503.

7 Deshmuckh P, Ramsey L, Garewal HS. Ki-67 labeling index is a more reliable measure of solid tumor proliferative activity than tritiated thymidine labeling. Am $\mathcal{f}$ Clin Pathol 1990;94:192-5.

8 Mothersill C, Seymour CB, O'Brien A, Hennessy T. Proliferation of normal and malignant human epithelia cells post irradiation. Acta Oncol 1991;30:851-8.

9 Nakano T, Oka K. Transition of Ki-67 index of uterine cervical tumors during radiation therapy. Immunohistochemical study. Cancer 1991;68:517-23.

10 Wahi PN, Cohen B, Luthra UK, Torloni H. Histological typing of oral and oropharyngeal tumours. In: International histological classification of tumours. 4 Geneva: World Health Organization, 1971

11 UICC: TNM classification of malignant tumours Hermanek P, Sobin LH eds. Berlin: Springer-Verlag
1987.

12 Hsu SM, Raine L, Fanger H. Use of avidin biotin peroxi- dase complex (ABC) in immunoperoxidase technique: a comparison between $\mathrm{ABC}$ and unlabeled antibody (PAP) procedures. F Histochem Cytochem 1981;29: 577-80

13 Moss WT, Brand WN, Battifora $H$. The oral cavity, oropharynx, and salivary and mucous gland. In: Radiation oncology. Rationale, technique, results. St. Louis: CV Mosby Company. 1979:83-146.

14 Hall PA, Richards MA, Gregory WM, D'Ardenne AJ Lister TA, Stansfield AG. The prognostic value of Ki67 immunostaining in non-Hodgkin's lymphoma. $\mathcal{f}$ Pathol 1988;154:223-35.

15 Sahin AA, Ro J, Ro JY, Blick MB, et al. Ki-67 immunostaining in node-negative stage I/II breast carcinoma. Significant correlation with prognosis. Cancer 1991;68: 549-57.

16 Sinclair WK. Cyclic $x$-ray responses in mammalian cells in vitro. Radiation Res 1968;33:620-43.

17 Swanson SA, Brooks J. Proliferation markers Ki-67 and p105 in soft-tissue lesions. Correlation with DNA flow p105 in soft-tissue lesions. Correlation with DNA flow
cytometric characteristics. Am $\mathcal{F}$ Pathol 1990;137: cytometric

18 Viehl P, Chevillard S, Mosser V, Donatini B, Magdelenat H. Ki67 index and S-phase fraction in human breas carcinomas. Comparison and correlations with prognostic factors. Am 7 Clin Pathol 1990;94:681-6.

19 Bush C, Price P, Norton J, et al. Proliferation in human bladder carcinoma measured by $\mathrm{Ki}-67$ antibody labelling: its potential clinical importance. $\mathrm{Br} \mathcal{F}$ Cancer 1991;64:357-60

20 Isola J, Kallioniemi DP, Korte JM, et al. Steroid receptors and Ki67 reactivity in ovarian cancer and in normal ovary: correlation with DNA flow cytometry, biochemiovary: correlation with DNA flow cytometry, biochemical receptor assay,

21 Kearsley JH, Furlong KL, Cooke RA, Waters MJ. An immunohistochemical assessment of cellular proliferation markers in head and neck squamous cell cancers. Br F Cancer 1990;61:821-7. 